RESEARCH REPORT

\title{
Youth smoking risk and community patterns of alcohol availability and control: a national multilevel study
}

\author{
Elissa R Weitzman, Ying-Yeh Chen, S V Subramanian
}

J Epidemiol Community Health 2005;59:1065-1071. doi: 10.1136/jech.2005.033183

\begin{abstract}
See end of article for authors' affiliations

.....................

Correspondence to: Dr E R Weitzman, Department of Society, Human Development and Health, Harvard School of Public Health, Landmark Center, 401 Park Drive, $\mathrm{Rm}$ 441, Boston, MA 02215, USA; eweitzma@ hsph.harvard.edu
\end{abstract}

Accepted for publication 25 July 2005

\begin{abstract}
Study objective: To test whether college youth smoking risks are independently associated with community patterns of alcohol availability and control.

Design: Hierarchical multilevel multivariable modelling of cross sectional survey data. Outcomes included self reported current (past 30 day) cigarette smoking and heavy episodic (binge) drinking.

Setting: 120 nationally representative US colleges.

Participants: 10924 randomly selected students.

Main results: Individual risks for smoking and binge drinking are independently associated with community patterns of alcohol availability, policy enforcement and control over and above individual perceptions about these factors, student and college characteristics, and school binge drinking rates. Youth exposed to high levels of alcohol availability are at higher risk of smoking (OR 3.61, 95\% Cl 1.75, 7.44) and binge drinking (OR $4.22,95 \% \mathrm{Cl} 2.25,7.93)$ than youth not so exposed; youth exposed to strongly enforced alcohol policy environments are at lower risk for smoking (OR $0.30,95 \% \mathrm{Cl} 0.16,0.57$ ) and binge drinking (OR $0.17,95 \% \mathrm{Cl} 0.10,0.31$ ) than youth not so exposed; youth exposed to communities with strong parental controls are at lower risk for smoking (OR $0.05,95 \% \mathrm{Cl} 0.01,0.23$ ) and binge drinking (OR $0.06,95 \% \mathrm{Cl} 0.01,0.21$ ) than youth not so exposed. Individual risks related to environmental exposures differ for youth with varying perceptions about alcohol availability and policy control.

Conclusions: Drinking environments in US college communities comprise strong independent risks for smoking. Smoking prevention models should be tested that include environmental drinking prevention strategies tailored to underlying perceptions and experiences of college youth.
\end{abstract}

D espite prevalent co-occurrence of tobacco and alcohol use among youth ${ }^{1-3}$ many prevention programmes are fragmented and focus on smoking or drinking. Fragmentation belies substantial overlap in smoking/drinking behaviours, clinical sample reports that these behaviours may cue each other, ${ }^{4-8}$ co-promotion of both products to youth, ${ }^{9}{ }^{10}$ and reports that head and neck cancer risks rise with simultaneous exposure to both substances beyond levels associated with substance specific use. ${ }^{11}{ }^{12}$ These factors suggest we integrate smoking with drinking prevention to target co-occurrence.

In the USA, college students comprise a population whose smoking and drinking behaviours may be particularly suited to a prevention model focused on co-occurrence. About one of every three young persons in the USA attends college or about 11 million youth annually. Nearly $33 \%$ of them use tobacco and $28.5 \%$ smoke cigarettes ${ }^{13} ; 80.7 \%$ drink and $44.4 \%$ binge on alcohol. ${ }^{14}$ In college, over $98 \%$ of smokers drink alcohol and the risks for any and heavy smoking in college are strongly and significantly related to frequent, heavy, and problem drinking. ${ }^{15}{ }^{16} \mathrm{Co}$-occurrence patterns are not surprising given that many drinking venues-bars, restaurants, and private parties-are also places where youth may gain access to tobacco, see smoking modelled, and experience peer pressure to smoke.

From a primary prevention perspective, few explicit models exist for targeting co-occurrence among college youth through environmental change strategies. Environmental strategies have been used to prevent youth smoking, ${ }^{17}{ }^{18}$ and are increasingly and successfully being used to reduce alcohol misuse and abuse. ${ }^{19}{ }^{20}$ For example, comprehensive community approaches to changing patterns of alcohol availability and promotion to college youth were recently shown to reduce heavy alcohol consumption and related harms in a 42 community quasi-experimental longitudinal study. ${ }^{21}$ Because smoking and drinking are correlated in college, ${ }^{15}$ and because these behaviours share risk factors related to settings and context, ${ }^{10}{ }^{22}$ we asked whether features of the alcohol environment might also affect smoking as a first step toward defining an environmental strategy targeting co-occurrence in college. We asked this question from the perspective of investigating the effects of the alcohol environment on smoking (rather than the converse) because of the two substances, alcohol is more widely used, illegal until age 21 (compared with 18 for tobacco), widely promoted, and readily available. Indeed it forms the centre of social life for many college youth.

Taking into consideration the dominant ecology of alcohol in college and the co-occurrence there of smoking and drinking, we investigated whether community patterns of alcohol availability and control are independently associated with smoking — and drinking_-among a national sample of college youth. We sought to answer this question by estimating the simultaneous effect on individual risks for smoking and drinking of measures of the drinking environment, taking advantage of multilevel multivariable modelling approaches and a clustered or hierarchical national dataset. Multilevel multivariable models allow us to examine effects on smoking behaviours of measures of the drinking environment net their effects on drinking behaviours (and vice versa) while providing estimators with lower variances than in separate modelisation. Using these models we tested hypotheses that smoking risks are lower in settings where it is harder to access alcohol, where policies governing alcohol use are strongly enforced, and where consequences for alcohol's misuse are expected to be salient. Because 


\begin{tabular}{|c|c|c|c|c|c|}
\hline Individual level $(n=10924)$ & $\begin{array}{l}\text { Binge } \\
\text { drinking }\end{array}$ & Smoking & $\begin{array}{l}\text { Ease of } \\
\text { availability }\end{array}$ & $\begin{array}{l}\text { Policy } \\
\text { enforcement }\end{array}$ & $\begin{array}{l}\text { Expectation of } \\
\text { parental } \\
\text { notification }\end{array}$ \\
\hline Binge drinking & 1.00 & & & & \\
\hline Smoking & $0.37^{* * *}$ & 1.00 & & & \\
\hline Ease of availability & $0.23^{\star \star *}$ & $0.15^{\star \star *}$ & 1.00 & & \\
\hline Policy enforcement & 0.01 & -0.0001 & $-0.05^{\star \star *}$ & 1.00 & \\
\hline $\begin{array}{l}\text { Expectation of parental } \\
\text { notification }\end{array}$ & $-0.08^{* * *}$ & $-0.05^{* \star *}$ & $-0.07^{* * *}$ & $0.14^{\star \star *}$ & 1.00 \\
\hline \multicolumn{6}{|l|}{ Contextual level $(n=120)$} \\
\hline Binge drinking & 1.00 & & & & \\
\hline Smoking & $0.57^{* * *}$ & 1.00 & & & \\
\hline Ease of availability & $0.48^{* * *}$ & $0.37^{* * *}$ & 1.00 & & \\
\hline Policy enforcement & -0.003 & $0.16^{* * *}$ & $-0.16^{* * *}$ & 1.00 & \\
\hline $\begin{array}{l}\text { Expectation of parental } \\
\text { notification }\end{array}$ & $-0.32^{\star \star *}$ & $-0.16^{* \star *}$ & $-0.15^{\star * *}$ & $0.37^{* * *}$ & 1.00 \\
\hline
\end{tabular}

contextual measures of the drinking environment have not been fully examined in relation to heavy or binge drinking and because of their high relevance for prevention, we examined effects on both smoking and binge drinking outcomes. We also sought to explore differential associations of alcohol availability and control on individual risks for smoking and drinking among youth with varying perceptions and beliefs about alcohol's availability and sensitivities to its control. Consistent with social ecological theory as applied to substance use, ${ }^{23-27}$ we hypothesised substantial interplay between individuals and their environments-and we expected to see variation in affects among youth with different perceptions exposed to similar environments. Results would support longitudinal study of effects on smoking of environmental drinking prevention programmes and testable interventions in this area.

\section{METHODS}

\section{Source of data}

Data for this study were drawn from the 2001 Harvard School of Public Health College alcohol study (CAS), an anonymous self report mailed survey that has been administered four times to a nationally representative sample of American college students. ${ }^{14}$ The survey was originally administered in 1993 to random samples of full time undergraduate students at a sample of 140 four-year colleges and universities. The 2001 CAS surveyed 10924 students at 120 of the colleges that participated in each of the previous three surveys. The attrition of 20 schools largely reflects institutions' inabilities to provide a sample of students and mailing addresses to meet the time constraints of the survey. ${ }^{14}$ The overall response rate in the 2001 survey was $50 \%$ (range 22\%$86 \%$ ). Further details about the survey methodology and sample are published elsewhere. ${ }^{14}{ }^{28}$ CAS survey administration and data collection were overseen and approved by the HSPH Human Subjects Committee and Institutional Review Board that has provided approval for ongoing analyses of project data.

\section{Outcome measures Smoking}

To assess cigarette smoking, students were asked how often, if ever, they had used cigarettes. The exact question read, "How often, if ever, have you used any of the drugs listed below? Do not include anything you used under a doctor's orders" A matrix of possible substances is provided that includes "cigarettes". Students are asked to select any of the following five responses for each possible response in the matrix, including cigarettes: "never used", "used but not in past 12 months", "used, but not in past 30 days" or "used in past 30 days." Current smokers were defined as those who ever used cigarettes in the past 30 days, consistent with previous reports..$^{29}$

\section{Binge drinking}

We used a sex specific definition of binge drinking in which, among men, binge drinking was defined as consumption of five or more drinks in a row at least once in the past two weeks and four or more drinks in a row during that period for women. ${ }^{30}$ The CAS questionnaire instructed participants to define a "drink" as a $12 \mathrm{oz}(360 \mathrm{ml})$ bottle or can of beer, a 4 oz $(120 \mathrm{ml})$ glass of wine, a $12 \mathrm{oz}(360 \mathrm{ml})$ bottle or can of wine cooler, or a shot $(1.25 \mathrm{oz}$ or $37 \mathrm{ml})$ of liquor either straight or in a mixed drink.

\section{Independent variables}

Three contextual measures were used to describe patterns of alcohol availability and control for students at each surveyed college. Measures were created from aggregated responses at the school level to questions about: perceived ease of alcohol availability, strength of alcohol policy enforcement, expectation of parental notification by the school for being caught illegally obtaining alcohol. The three indicators were selected a priori to reflect conceptually distinct components of comprehensive environmental prevention approach following social behavioural models of substance use in college. Each contextual measure was construed to indicate important aspects of the alcohol environment at each college as might best be represented by the perceptions and experiences of a representative sample of youth within it, independent of a given respondent's reports. In dichotomising all three contextual variables, we selected cut off point values that represented emphatic perceptions or opinions of surveyed youth to better distinguish among campus communities that espouse versus with enact various policies and practices related to the drinking environment. Operational definitions for each independent variable include:

(1) Perceived ease of alcohol availability at the school level, operationalised as the percentage of students who reported alcohol is "very easy" to obtain at each college. The exact question on which this indicator was based read, "How easy is it for you to obtain alcohol?" Students were asked to choose among five responses: "very difficult, difficult, easy, very easy, don't know."

(2) Perceived alcohol policy enforcement at the school level, operationalised as the percentage of students reporting that the school alcohol policy was "strongly enforced" in each college. The exact question read, "In your opinion, how strongly 
Table 2 Individual and contextual correlates of smoking and binge drinking, before and after adjusting for school binge rate

\begin{tabular}{|c|c|c|c|c|c|c|c|c|c|c|c|c|}
\hline & \multicolumn{4}{|c|}{ Model A } & \multicolumn{4}{|c|}{ Model B: contextual predictor included } & \multicolumn{4}{|c|}{ Model C: adjusted for school binge rate } \\
\hline & \multicolumn{2}{|c|}{ Current smoking } & \multicolumn{2}{|c|}{ Binge drinking } & \multicolumn{2}{|c|}{ Current Smoking } & \multicolumn{2}{|c|}{ Binge drinking } & \multicolumn{2}{|c|}{ Current Smoking } & \multicolumn{2}{|c|}{ Binge drinking } \\
\hline & OR & $95 \% \mathrm{Cl}$ & OR & $95 \% \mathrm{Cl}$ & OR & $95 \% \mathrm{Cl}$ & OR & $95 \% \mathrm{Cl}$ & OR & $95 \% \mathrm{Cl}$ & OR & $95 \% \mathrm{Cl}$ \\
\hline \multicolumn{13}{|c|}{$\begin{array}{l}\text { (1) Ease of availability ("very } \\
\text { easy") }\end{array}$} \\
\hline Individualt & $1.97^{* * *}$ & $(1.78,2.18)$ & $2.45^{* * *}$ & $(2.23,2.69)$ & $1.94^{* \star *}$ & $(1.75,2.16)$ & $2.40^{\star \star \star}$ & $(2.19,2.64)$ & $1.95^{* \star *}$ & $(1.76,2.16)$ & $2.41^{* \star *}$ & $(2.19,2.65)$ \\
\hline Contextual & & & & & $5.36 * * *$ & $(2.71,10.60)$ & $22.62^{* * *}$ & $(9.93,51.53)$ & $3.61^{* * *}$ & $(1.75,7.44)$ & $4.22^{\star * \star}$ & $(2.25,7.93)$ \\
\hline \multicolumn{13}{|c|}{ School binge rate (base: low) } \\
\hline High ( $\geqslant 50 \%)$ & & & & & & & & & $1.26^{*}$ & $1.04,1.53)$ & $2.51^{* * *}$ & $(2.12,2.98)$ \\
\hline Middle $(35 \%-49.99 \%)$ & & & & & & & & & 1.05 & $(0.88,1.25)$ & $1.55^{\star \star *}$ & $(1.32,1.81)$ \\
\hline \multicolumn{13}{|l|}{$\begin{array}{l}\text { (2) Policy enforcement } \\
\text { ("strongly enforced") }\end{array}$} \\
\hline Individualt & 1.11 & $(0.98,1.26)$ & $1.28^{\star \star *}$ & $(1.14,1.45)$ & 1.14 & $(1.00,1.29)$ & $1.33^{\star \star \star}$ & $(1.18,1.51)$ & 1.14 & $(1.00,1.30)$ & $1.33^{* * *}$ & $(1.17,1.50)$ \\
\hline Contextual & & & & & $0.26^{* *}$ & $(0.13,0.53)$ & $0.10^{* * *}$ & $(0.04,0.26)$ & $0.30^{* *}$ & $(0.16,0.57)$ & $0.17^{* * *}$ & $(0.10,0.31)$ \\
\hline \multicolumn{13}{|c|}{ School binge rate (base: low) } \\
\hline High $(\geqslant 50 \%)$ & & & & & & & & & $1.56^{* *}$ & $(1.30,1.86)$ & $3.14^{* * *}$ & $(2.67,3.70)$ \\
\hline Middle (35\%-49.99\%) & & & & & & & & & 1.18 & $(0.99,1.42)$ & $1.76^{* * *}$ & $(1.49,2.07)$ \\
\hline \multicolumn{13}{|l|}{$\begin{array}{l}\text { (3) Expectation of parental } \\
\text { notification ("very likely") }\end{array}$} \\
\hline Individualt & $0.68^{* *}$ & $(0.55,0.85)$ & $0.60^{* * *}$ & $(0.50,0.73)$ & $0.71^{* *}$ & $(0.57,0.88)$ & $0.63^{* * *}$ & $(0.52,0.77)$ & $0.71^{* *}$ & $(0.57,0.88)$ & $0.63^{* * *}$ & $(0.52,0.76)$ \\
\hline Contextual & & & & & $0.02^{\star \star \star}$ & $(0.005,0.10)$ & $0.002^{\star \star \star}$ & $(0.003,0.01)$ & $0.05^{\star \star \star}$ & $(0.01,0.23)$ & $0.06^{* * *}$ & $(0.01,0.21)$ \\
\hline \multicolumn{13}{|c|}{ School binge rate (base: low) } \\
\hline High $(\geqslant 50 \%)$ & & & & & & & & & $1.36^{*}$ & $(1.12,1.64)$ & $2.75^{\star \star *}$ & $(2.31,3.27)$ \\
\hline Middle (35\%-49.99\%) & & & & & & & & & 1.08 & $(0.90,1.29)$ & $1.61^{* * *}$ & $(1.37,1.91)$ \\
\hline
\end{tabular}

Models A, B, C control for sex, age, race, SES, student membership, residence (off campus or not), geographical region, and college response rate. †Base is 1.00 and includes for model (1) youth reporting alcohol is "very difficult, difficult, easy", to obtain or "don't know," for model (2) school alcohol policies are "enforced, weakly enforced, not enforced at all and don't know/no school policy," and for model (3) parental notification is "somewhat likely, somewhat unlikely, very unlikely, don't know." * $p<0.05,{ }^{* *} p<0.01,{ }^{* * *} p<0.0001$.

does your school enforce its alcohol policy?" Students were asked to choose among five responses: "strongly enforced, enforced, weakly enforced, not enforced at all and don't know/no school policy."

(3) Expectation of parental notification at the school level, operationalised as the percentage of students who reported that parental notification by the school would be "very likely" if a student were caught using a fake ID to purchase alcohol. The exact question read, "If a student is caught using a fake ID to purchase alcohol off campus in the city or town where your college is located, how likely to happen are each of the following consequences?" A matrix of possible responses is provided that includes "Parents are notified." Students are asked elect any of the following five responses for each possible response in the matrix, including parental notification: "very likely, somewhat likely, somewhat unlikely, very unlikely, don't know."

\section{Covariates}

A series of potential confounders were included in all analyses, including variables describing respondents' sex, age, race, socioeconomic status measured as parents' educational attainment (high: both parents had college degree, middle: one parent had college degree, low: neither father nor mother had college degree), fraternity/sorority membership, student's residence (off campus or on campus). Additionally all analyses controlled for the geographical region of the college (western or non-western) given regional variation in binge drinking. ${ }^{14}$ To protect against possible threats to the validity of the research from non-response bias, all analyses are controlled for school response rate. Final models adjusted for main effects of individual perceptions about alcohol availability (model 1), policy enforcement (model 2), or parental notification (model 3), and a categorical value of college binge rate (medium or high compared with low) to assess the net effects of contextual measures on outcomes (see below).

\section{Analysis}

We examined results from two correlation matrices generated using Spearman's correlation estimation as a first step in our work. The first matrix describes correlations among individual reports $(n=10924)$ of current smoking, binge drinking, and perceptions about alcohol's availability, policy enforcement and parental notification (table 1, part A). The second matrix reflects correlations among contextual measures $(\mathrm{n}=120)$ of these variables (that is, campus level percentages) (table 1, part B). Next, multivariate multilevel logistic models based on a logit-link function were used to evaluate the simultaneous effects on individual risks for smoking and binge drinking of individual perceptions about alcohol availability, policy enforcement, and likelihood of parental notification if caught illegally trying to obtain alcohol (table 2 , models A). Separate models were run for each predictor variable. To each of these models we added the matching contextual measure reflecting community level reports or norms about the variable of interest-alcohol availability, policy enforcement, or parental notification, construing from these measures larger characteristics of the alcohol environment at each school, and controlling in these models for the main effects of individual perceptions about availability, enforcement and controls on drinking from which contextual measures were built along with demographic and college control variables (table 2, models B). Finally, we added to these models a measure of school binge rate, to assess whether the effect on smoking and binge drinking of contextual measures operated through or was explained by a given college's binge rate (table 2 , models $\mathrm{C}$ ). All the models assumed that individual behaviours (smoking, binge drinking) are the corresponding probability plus a random individual specific error, with variance equal to 1 (that is, random intercept model). We also examined results for a final model including all three contextual measures and their main effects plus covariates, to assess the strength of each contextual measure in the presence of the others.

All analyses were fitted using multilevel software-MLwin (version 1.10.0006) $)^{31}$ with penalised quasilikelihood (PQL) second order estimation procedures applied. Multivariate multilevel analysis, an extension to the multilevel analysis, can estimate two outcomes simultaneously in one multilevel model as done here to estimate the effects on smoking independent of the effects on drinking (and vice versa). Lastly, we explored whether the effects of contextual variables varied by individual perceptions, testing cross level interactions built from individual perceptions about 

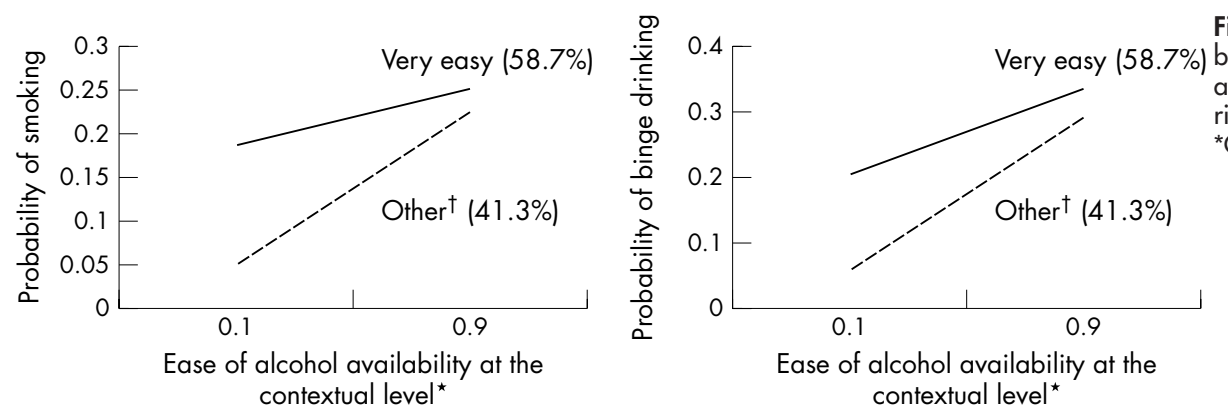

Figure 1 Cross level interactions between contextual measures of alcohol availability and controls and individual risks for smoking and binge drinking. ${ }^{*}$ Cross level interaction $p<0.05$.
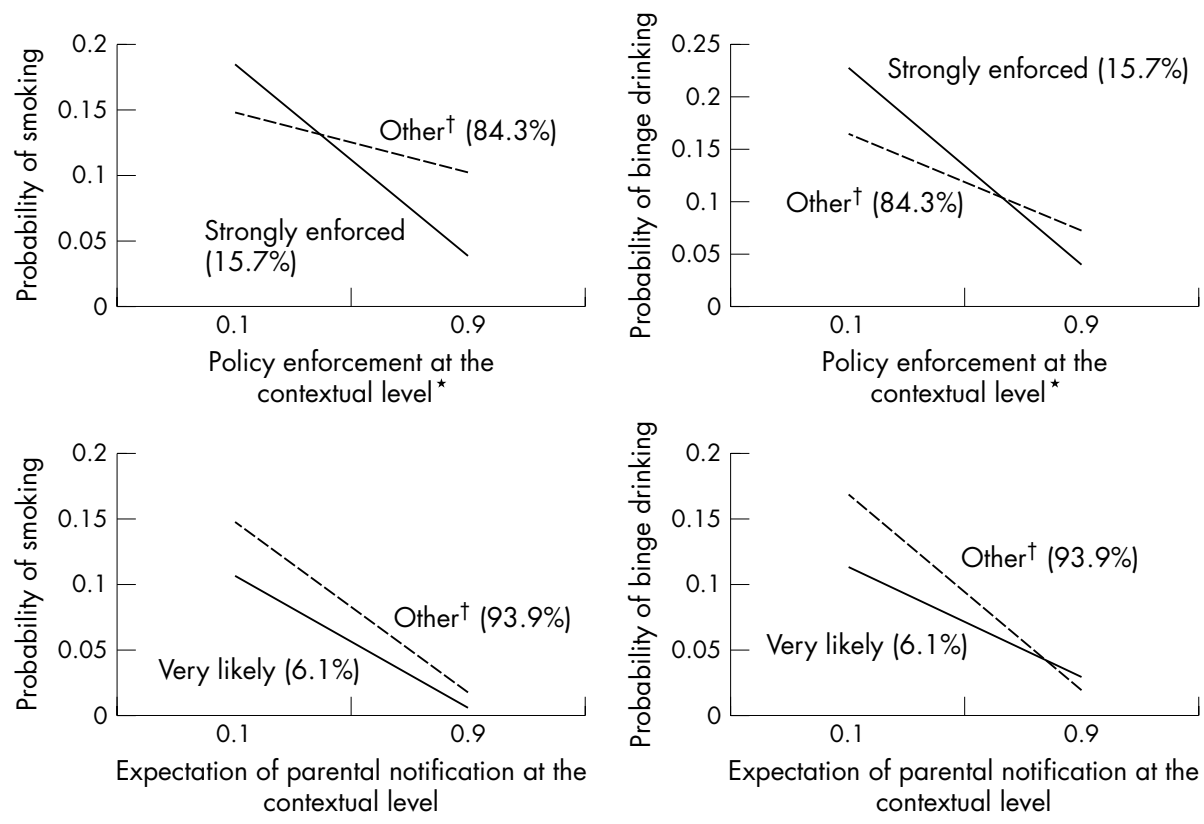

availability, enforcement, and parental notification and contextual measures of the same in multilevel models that controlled for all relevant covariates. Cross level interactions were tested separately for both smoking and binge drinking and are depicted in figure 1. Analyses omitted observations for which measures of the dependent variables were missing, including 65 cases $(0.6 \%)$ missing data for smoking and 116 ( $1.1 \%)$ missing data for binge drinking.

\section{RESULTS}

The average prevalence of current smoking for the total sample was $25.1 \%$ and the average prevalence of binge drinking was $42.9 \%$. At the college level, smoking rates ranged between $0.6 \%$ and $55 \%$ and binge drinking rates ranged between $0.6 \%$ and $80 \%$. About $58.7 \%(n=6386)$ of the students reported that alcohol was very easy to obtain; $15.3 \%(n=1663)$ reported that their school alcohol policy was strongly enforced; and $6.1 \%(n=661)$ reported that parental notification was very likely if a student was caught using a fake ID to purchase alcohol.

Among those who reported that alcohol was "very easy" to obtain, $30.8 \%$ were current smokers and $52.4 \%$ were binge drinkers. Among those who reported that their school alcohol policy was "strongly enforced," $25.0 \%$ currently smoke and $44.4 \%$ binge drink. Among those who reported that parental notification was "very likely" in the event a student was caught illegally using a fake ID to purchase alcohol, 16.3\% currently smoke and $26.9 \%$ binge drink.

Correlations among individual perceptions about alcohol availability, policy enforcement, and controls on drinking (independent variables) and individual risks for smoking and binge drinking were low (table 1, part A). Correlations among contextual measures of alcohol availability, enforcement and controls on drinking and campus prevalence levels of smoking and drinking were moderate (table 1, part B). At the individual level, positive correlations were seen between availability and both outcomes; negative correlations were seen between parental notification and both outcomes. Positive correlations were seen among availability and both study outcomes, and between enforcement and smoking. At the contextual level, negative correlations were seen between policy enforcement and binge drinking as well as between parental notification and both outcomes.

Table 2 shows the sequential modelling results for the effects of the three types of contextual measures of availability, enforcement, and controls on individual odds of current smoking and binge drinking. Looking first at individual reports only (models A), compared with their peers reporting otherwise, youth reporting alcohol was "very easy" to obtain were more likely to smoke and binge drink; youth reporting their school alcohol policy was "strongly enforced" were more likely to binge drink, but not to smoke; finally, youth reporting parental notification was "very likely" were less likely to smoke and binge drink. These results were unchanged by the addition of contextual measures of these variables. Contextual measures were substantially and significantly associated with individual risks for both smoking and binge drinking (models B). Youth exposed to environments in which alcohol was widely perceived to be readily available for example were more likely to smoke and to binge drink than youth in other environments even after controlling for their own perceptions 
about alcohol availability (model B, first row). For example, the adjusted OR for smoking increases from 2.32 to 2.74 and the adjusted OR for binge drinking increases from 4.76 to 6.50 when the percentage of students reporting alcohol is "very easy" to obtain increases from $50 \%$ to $60 \%$ in model B. Youth exposed to environments in which alcohol policies were widely perceived as "strongly enforced" were significantly less likely to smoke and significantly less likely to binge drink than were youth in other environments. In the case of binge drinking, this finding runs counter in direction to the effect of individual perceptions about policy enforcement (model B, second row). Youth exposed to environments in which large percentages of the community expected that parental notification for being caught illegally purchasing alcohol were "very likely" were protected from both smoking and binge drinking relative to risks among youth in communities with lower levels of such expectations (model $\mathrm{B}$, third row). Controlling for the baseline level of drinking in the community modified the effects of contextual measures (model C, all rows), which nevertheless remained strongly significant. In summary, all three contextual measures of the alcohol environment independently predicted individual risks of smoking and binge drinking, over and above the effects of individual perceptions about these factors, compositional characteristics of the students, college characteristics, and binge drinking rates.

When all three contextual variables and main effects were entered in the model with the full set of covariates, the odds for current smoking and binge drinking for contextual predictors were as follows by measure: "very easy" availability $2.97(1.40,6.28) \quad(\mathrm{p}<0.01)$ and $3.03 \quad(1.55,5.92)$ $(\mathrm{p}<0.01)$; "strongly enforced" alcohol policies $1.12(0.52$, $2.40)$ and $0.59(0.30,1.17)$; "very likely" parental notification $0.10(0.02,0.54)(\mathrm{p}<0.01)$ and $0.21(0.05,0.94)(\mathrm{p}<0.05)$. Odds for individual level predictors remained very similar to their values in the separate models.

Findings about the effects of exposure to alcohol contexts were not uniform, but varied among youth with different perceptions about the drinking world (fig 1). Specifically, the adjusted odds for both smoking and binge drinking increased with exposure to environments with increasing levels of "very easy" alcohol availability for youth who did and youth who did not perceive this. Effects on both outcomes were most evident among the $41.3 \%$ of youth who did not report

\section{What this paper adds}

- There is growing evidence that features of drinking environments, including patterns of alcohol availability, policies, and controls, affect drinking. Ample evidence also exists describing how drinking environments affect alcohol consumption among college youth who are at peak risk of heavy and harmful drinking.

- This paper goes beyond existing research to show that features of drinking environments around youth independently affect their risks for smoking. Furthermore, this paper describes variations in the effects on smoking (as well as binge drinking) of environmental exposures related to alcohol availability and control for youth with different underlying beliefs and perceptions about alcohol's availability and control. In so doing, this paper provides evidence supportive of environmentally oriented prevention programmes targeting co-occurring smoking and drinking among college youth. "very easy" alcohol availability as evidenced by the larger slope in figure 1 (top two graphs) $(\mathrm{p}<0.05)$. Exposure to environments in which drinking policies are strongly enforced was associated with significantly reduced risks for smoking and binge drinking and significant $(p<0.05)$ cross level interactions were found for both outcomes. Effects are sharpest for the $15.7 \%$ of youth reporting strong alcohol policy enforcement (figure 1, middle two graphs). Cross level interactions were not significant for contextual measures of parental notification although the general trend seems to support a protective effect (figure 1, bottom two graphs).

\section{DISCUSSION}

Exposure to college communities in which alcohol was very easy to obtain was associated with substantially greater risk for both smoking and binge drinking among a nationally representative sample of youth $(n=10$ 924) drawn from 120 different communities. Increased risks for smoking and binge drinking for youth with this exposure persisted even after controlling for the effects of individual perceptions about alcohol's availability and after controlling for the prevalence of binge drinking at the college level. Exposure to environments with strong alcohol policy enforcement and widespread expectations of parental notification for being caught trying to illegally obtain alcohol were associated with diminished risks for smoking and binge drinking in similarly constructed models. When combined into a single multilevel multivariable model it seems that contextual measures of alcohol availability and policy enforcement may be explaining the same underlying construct because effects for enforcement become insignificant. The protective effect of parental notification retains its significance, suggesting a separate social control mechanism.

Two factors are of interest: high risk drinking is powerfully associated with features of the alcohol environment, consistent with other reports. ${ }^{20} 3233$ Additionally, characteristics of the alcohol environment are associated with sizeable independent risks for smoking after considering their effects on drinking and after considering the effects on outcomes of individual perceptions about alcohol's availability and control. Individual perceptions about alcohol availability, policy enforcement, and parental notification were also associated with smoking and drinking, however the magnitude of observed effects for these factors was very small and our ability to detect them may reflect the very large sample size.

We found significant cross level interactions between individual perceptions about alcohol availability and contextual patterns of availability and control as they affect both smoking and binge drinking. Interactions took several forms. In one scenario, youth who did not personally perceive that alcohol was easily available (about $41 \%$ of youth) but who were exposed to environments in which availability was reportedly high, exhibited strong statistically significant increases in risk for smoking and binge drinking. This

\section{Policy implications}

Community patterns of alcohol availability and control should be considered important components of a comprehensive strategy of smoking prevention among college youth. Broader patterns of smoking/drinking co-occurrence among college youth should be considered when designing preventing programmes targeting either behaviour. Optimal and efficient use of prevention resources may require integration of prevention efforts across substance use areas as well as tailoring of prevention messages to underlying beliefs and perceptions of youth. 
finding shows the potential power of aspects of the drinking world to affect smoking and drinking risk among youth who might otherwise not smoke or drink, consistent with reports about associations between alcohol availability and risks for acquiring binge drinking in college ${ }^{33}$ and association between tobacco promotions and risks for acquiring smoking in college. ${ }^{34}$ In other scenarios, exposure to communities with strongly enforced drinking policies was associated with reduced risks for both smoking and binge drinking, with particularly strong associations among youth who perceived strong enforcement, showing an intensification or synergy in protective effects. Cross level interactions recently were reported for alcohol use ${ }^{35}$ and these findings may be the first evidence of such interactions across substances.

While all of these findings reflect cross sectional associations they may help us move from considering the interrelation of smoking with drinking among college youth toward a deeper exploration of the ways in which features of the drinking world may affect smoking as well as drinking in longitudinal and experimental models. Several topics for future investigation are suggested, including exploration of the mechanisms by which generalised effects on smoking exist. Studies about the ways in which exposure to drinking environments may present opportunities for youth to obtain other substances including tobacco, experience heavy promotions for other substances, and model more deviant or drug using peers, all potential risk factors, ${ }^{36}$ are suggested. Natural history and longitudinal studies are similarly suggested that describe effects on smoking related norms, beliefs, and behaviours of interventions designed to restrict youth access to alcohol through community policies or social controls, such as those governing access to bars, alcohol outlets, and purchase of alcohol. Similarly longitudinal study of the effect on smoking and drinking of drinking related parental notification policies that have gained popularity in US colleges may advance our understanding of generalised protective effects of parental controls on health risk behaviours among youth who no longer reside with their parents. In this study, few youth $(6.1 \%)$ reported that parental notification was very likely however contextual effects of this variable were powerful. Effects challenge the widespread assumption that parental authority over youth diminishes when youth leave home for college. Rather, parental notification may be a potentially important public policy tool. Its use however requires that colleges walk a fine line between invoking parental authority and protecting independence and confidentially.

In considering the design and implementation of effective prevention strategies targeting smoking and drinking, it is important to note that most probably one size will not fit all. Cross level interactions suggest that youth are differently affected by availability and environmental controls depending on their sensitivities and beliefs. Variations may reflect underlying differences in the degree to which youth are bonded to the larger community and therefore sensitive and conforming to social controls on substance use and the perceived consequences of breaking rules, as predicted by social learning, development, and control theories. ${ }^{23} 2636$ Variations may also reflect differences among youth who have already experimented with substances to become regular or problem users. These youth may be more adept at procuring alcohol (or tobacco) and/or less sensitive to social controls or sanctions governing substance use. These nuances should be considered when designing prevention efforts.

This study is strengthened by use of a large national sample, representative institutional sampling frame, and analytical methods including multilevel multivariate modelling. ${ }^{37}$ Nevertheless, several limitations deserve mention. Data are cross sectional and questions about causal effect of exposures and outcomes cannot be addressed-only suggested. Controlled prospective study methods are required to adequately address questions of causality and temporal sequencing. Bias may have been introduced to the study sample through non-response and attrition. However, a short form of the questionnaire sent to non-responders showed no difference in past year alcohol use and 30 day smoking rate between responders to the short form and those responding to the entire survey. ${ }^{38}{ }^{39}$ Variations in response rates by college and low student response rates at a few colleges may affect the representativeness of the samples. However, all analyses controlled for compositional characteristics of the study sample to limit the possibility that findings are confounded by sociodemographic or other college characteristics. Procedures to detect potential bias from non-response and attrition found none ${ }^{40}$ and response rates for individual schools are not associated with rates of smoking or binge drinking. ${ }^{142838}{ }^{39}$ Furthermore, response rate is controlled as a covariate in the analyses. Confidence in the validity of the CAS data is strengthened by the comparability of CAS rates of multiple health risk behaviours including tobacco use, illicit substance use, depressive symptoms, and binge drinking with rates of these behaviours obtained by other national surveys. ${ }^{41-46}$ All results are based on self report mailed questionnaires, which are subject to response bias. However, self report surveys are commonly used in examining alcohol use and are generally considered valid. ${ }^{46-48}$ Findings from this study may not generalise to youth beyond those enrolled in four year colleges in the USA. Finally, we used aggregated reports of students in their campuses as contextual measures-placing confidence in collective perceptions as a fair reflection of the larger context. This approach has precedent and is generally considered valid. ${ }^{49}$

\section{CONCLUSIONS}

Drinking environments in US college communities are strongly and independently associated with risks for smoking, over and above beyond their effects on drinking. Thus effective smoking prevention programmes for college youth might include elements of environmental drinking prevention models. Optimal prevention strategies for college youth may be ones that explicitly target co-occurring smoking/ drinking, considering influences across social levels. Strategies may need to consider the heterogeneity in substance related experiences, perceptions, and beliefs among college youth so that prevention messages, controls, and programmes are appropriately tailored.

\section{ACKNOWLEDGEMENTS}

We thank Jeff Hansen, Toben F Nelson, and Henry Wechsler of the Harvard School of Public Health (HSPH) for their help with data preparation $(\mathrm{JH})$ and for their thoughtful and generous comments on this project and manuscript (TFN and HW). We also thank the anonymous reviewers of this manuscript for their careful reading and helpful suggestions.

\section{Authors' affiliations}

E R Weitzman, Y-Y Chen, S V Subramanian, Department of Society, Human Development and Health, Harvard School of Public Health, Boston, Massachusetts, USA

Y-Y Chen, Taipei City Psychiatric Centre, Taipei, Taiwan

Funding: this study was supported by a grant from the Robert Wood Johnson Foundation.

Competing interests: none declared. 


\section{REFERENCES}

1 Istvan J, Matarazzo JD. Tobacco, alcohol, and caffeine use: a review of their relationships. Psychol Bull 1984;95:301-26.

2 Koopmans JR, van Doornen $\sqcup$, Boomsma DI. Association between alcohol use and smoking in adolescent and young adult twins: a bivariate genetic analysis. Alcohol Clin Exp Res 1997;21:537-46.

3 Hoffman JH, Welte JW, Barnes GM. Co-occurrence of alcohol and cigarette use among adolescents. Addict Behav 2001;26:63-78.

4 Rohsenow DJ, Monti PM, Colby SM, et al. Effects of alcohol cues on smoking urges and topography among alcoholic men. Alcohol Clin Exp Res 1997;21:101-7.

5 Gulliver SB, Rohsenow DJ, Colby SM, et al. Interrelationship of smoking and alcohol dependence, use and urges to use. J Stud Alcohol 1995;56:202-6.

6 Burton SM, Tiffany ST. The effect of alcohol consumption on craving to smoke. Addiction 1997;92:15-26.

7 Palfai TP, Monti PM, Ostafin B, et al. Effects of nicotine deprivation on alcoholrelated information processing and drinking behavior. J Abnorm Psychol 2000; 109:96-105.

8 Mintz J, Boyd G, Rose JE, et al. Alcohol increases cigarette smoking: a laboratory demonstration. Addict Behav 1985;10:203-7.

9 Sepe E, Ling PM, Glantz SA. Smooth moves: bar and nightclub tobacco promotions that target young adults. Am J Public Health 2002;92:414-19.

10 Ling PM, Glantz SA. Why and how the tobacco industry sells cigarettes to young adults: evidence from industry documents. Am J Public Health 2002;92:908-16.

11 Chang HW, Ling GS, Wei WI, et al. Smoking and drinking can induce p15 methylation in the upper aerodigestive tract of healthy individuals and patients with head and neck squamous cell carcinoma. Cancer 2004;101:125-32.

12 Menvielle G, Luce D, Goldberg $P$, et al. Smoking, alcohol drinking and cancer risk for various sites of the larynx and hypopharynx. A case-control study in France. Eur J Cancer Prev 2004;13:165-72.

13 Rigotti NA, Lee JE, Wechsler H. US college students' use of tobacco products: results of a national study. JAMA 2000;284:699-705.

14 Wechsler $\mathrm{H}$, Lee JE, Kuo $M$, et al. Trends in college binge drinking during a period of increased prevention efforts: findings from 4 Harvard School of Public Health College alcohol study surveys, 1993-2001. J Am Coll Health 2002;50:203-17

15 Weitzman ER, Chen Y. The co-occurrence of alcohol and tobacco use in a national sample of youth in college settings. Drug Alcohol Depend (in press).

16 Jones SE, Oeltmann J, Wilson TW, et al. Binge drinking among undergraduate college students in the United States: implications for other substance use. J Am Coll Health 2001;50:33-8.

17 Chaloupka F. Clean indoor air laws, addiction, and cigarette smoking. Applied Economics 1992;24:193-205.

18 Pollack JB, Ahlstrom A, Lantz PM, et al. Investing in youth tobacco control: a review of smoking prevention and control strategies. Tob Control 2000;9:47-63.

19 Wechsler H, Kelley K, Weitzman E, et al. What colleges are doing about student binge drinking: a survey of college administrators. J Am Coll Health 2000;48:219-26.

20 Toomey TL, Wagenaar AC. Environmental policies to reduce college drinking options and research findings. J Stud Alcohol Supp/ 2002;14:193-205.

21 Weitzman ER, Nelson TF, Lee $\mathrm{H}$, et al. Reducing drinking and related harms in college: evaluation of the "A Matter of Degree" program. Am J Prev Med 2004;21:187-96.

22 Simons-Morton B, Haynie DL, Crump AD, et al. Peer and parent influences on smoking and drinking among early adolescents. Health Educ Behav $2001 ; 28: 95-107$.

23 Akers RL. Deviant behavior: a social learning approach. 2nd ed. Belmont: Wadsworth Press, 1977

24 Bandura A. Social foundations of thought and action: a social cognitive theory. Englewood Cliffs, NJ: Prentice-Hall, 1986

25 Bronfenbrenner U. The ecology of human development: experiments by nature and design. Cambridge, MA: Harvard University Press, 1979.
26 Lonczak HS, Huang B, Catalano RF, et al. The social predictors of adolescent alcohol misuse: a test of the social development model. J Stud Alcohol 2001;62:179-89.

27 Stokols D. Establishing and maintaining health environments: toward a social ecology of health promotion. Am Psychol 1992;47:6-22.

28 Wechsler H, Davenport A, Dowdall GW, et al. Health and behavioral consequences of binge drinking in college: a national survey of students on 140 campuses. JAMA 1994;272:1672-7.

29 Wechsler H, Rigotti NA, Gledhill-Hoyt J, et al. Increased levels of cigarette use among college students: a cause for national concern. JAMA 1998;280:1673-8

30 Wechsler H, Dowdall G, Davenport A, et al. A gender-specific measure of binge drinking among college students. Am J Public Health 1995;85:982-5.

31 Rasbash J, Browne W, Goldstein H, et al. A user's guide to MLwiN. London: Multilevel Models Project, Institute of Education, University of London, 2002.

32 Weitzman ER, Folkman A, Folkman KL, et al. The relationship of alcohol outlet density to heavy and frequent drinking and drinking-related problems among college students at eight universities. Health Place 2003;9:1-6.

33 Weitzman ER, Nelson TF, Wechsler H. Taking up binge drinking in college: the influence of personal, social and environmental factors. J Adolesc Health 2003;32:26-35.

34 Rigotti NA, Moran SE, Wechsler H. US college students' exposure to tobacco promotions: prevalence and association with tobacco use. Am J Public Health 2005;95: 138-44.

35 Kumar R, O'Malley PM, Johnston LD, et al. Effects of school-level norms on student substance use. Prev Sci 2002;3:105-24.

36 Hawkins JD, Catalano RF, Miller JY. Risk and protective factors for alcohol and other drug problems in adolescence and early adulthood: implications for substance abuse prevention. Psychol Bull 1992;12:64-105.

37 Subramanian SV, Kim DJ, Kawachi I. Covariation in the socioeconomic determinants of self rated health and happiness: a multivariate multilevel analysis of individuals and communities in the USA. J Epidemiol Community Health 2005;59:664-9.

38 Wechsler H, Lee JE, Rigotti NA. Cigarette use by college students in smokefree housing: results of a national study. Am J Prev Med 2001;20:202-7.

39 Wechsler H, Lee JE, Gledhill-Hoyt J, et al. Alcohol use and problems at colleges banning alcohol: results of a national survey. J Stud Alcohol $2001 ; 62: 133-41$

40 Wechsler H, Lee JE, Kuo M, et al. College binge drinking in the 1990s: a continuing problem results of the Harvard School of Public Health 1999 College alcohol study. J Am Coll Health 2000;48:199-210.

41 Gledhill-Hoyt J, Lee H, Strote J, et al. Increased use of marijuana and other illicit drugs at US colleges in the 1990s: results of three national surveys. Addiction 2000;95:1655-67.

42 Weitzman ER. Poor mental health/depression and associations with alcohol consumption: harms and abuse in a national sample of young adults in college. J Nerv Ment Dis 2004;192:269-77.

43 Douglas KA, Collins JL, Warren C, et al. Results from the 1995 National College health risk behavior survey. J Am Coll Health 1997;46:55-66.

44 Kessler RC, McGonagle KA, Zhao S, et al. Lifetime and 12-month prevalence of DSM-III-R psychiatric disorders in the United States. Arch Gen Psychiatry 1994:51:8-19.

45 Johnston LD, O'Malley PM, Bachman JG. National survey results on drug use from the monitoring the future study, 1975-1995. Vol II. College students and young adults. NIH publication no 98-4140, Rockville, MD: National Institute on Drug Abuse, 1997.

46 Cooper AM, Sobell MB, Sobell LC, et al. Validity of alcoholics' self-reports: duration data. Int J Addict 1981;16:401-6.

47 Frier MC, Bell RM, Ellickson PL. Do teens tell the truth? The validity of selfreport tobacco use by adolescents. RAND publication N-3291-CHF. Santa Monica, CA: RAND, 1991.

48 Midanik L. Validity of self report alcohol use: a literature review and assessment. Br J Addict 1988;83:1019-30.

49 Buckner JC. The development of an instrument to measure neighborhood cohesion. Am J Community Psychol 1988;16:771-91. 